
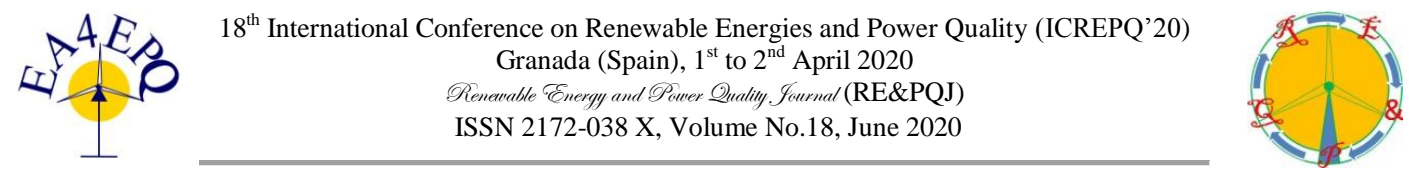

\title{
Ripple Minimization in a Quadratic Boost Converter: Software vs. Hardware solutions
}

\author{
G. Marsala ${ }^{1}$, V. Presti ${ }^{1}$, A. Sauro ${ }^{1}$, S. G. Scordato ${ }^{1}$, G. Vitale ${ }^{2}$ \\ ${ }^{1}$ INM, The Institute of Marine Engineering National Research Council of Italy, \\ via Ugo La Malfa 153, Palermo, Italy. Email: giuseppe.marsala@cnr.it; \\ ${ }^{2}$ ICAR, Institute for high performance computing and networking, National Research Council of Italy, \\ via Ugo La Malfa 153, Palermo, Italy. Email: gianpaolo.vitale@icar.cnr.it;
}

\begin{abstract}
In this work, the authors have studied a quadratic boost DC-DC converter to reduce its ripple in the output voltage and the input current. This aim has been obtained by implementing two different solutions: the hardware solution consists on the use of coupled inductors and a notch output filter, the software solution is based on a random PWM and uses uncoupled inductors. The two solutions show a different impact on the output voltage and in the input current ripple. The performance of proposed solutions is evaluated and compared by simulation analysis both in time and frequency domain.
\end{abstract}

Key words. Quadratic boost converter, ripple reduction, random modulation, filtering.

\section{Introduction}

The DC-DC switching converters are widely used as power electronic interfaces in renewable energy sources (RESs), as photovoltaic PV and fuel cells (FCs) systems. These sources represent a significant solution compared to the non-renewable energy ones because they do not pollute the air and the water, like way burning fossil fuels does. On the other hand, in general, these sources deliver low voltage, and a DC-DC converter is required for boosting this voltage to a suitable value. Besides, the input current and output voltage of the DC-DC converters are not pure DC quantities but exhibit a superimposed high-frequency ripple because of the inherent characteristic of switching operation of power devices. This ripple decreases the accuracy of the maximum power point tracking algorithm (MMPT) used in FCs and PV systems [1], reduces the FCs life-time and the output power available, increases the hydrogen consumption and can force the FCs to work in regions characterized by excessive losses and overheating [2-3]. The presence of the ripple makes DC-DC converter a source of electromagnetic interference (EMI) that can disturb nearby electric/electronic devices and deteriorate their normal operating conditions. The switching operation generates, in fact, high dv/dt and di/dt that cause both conducted and radiated EMI [4-5]. To mitigate these issues, the DC-DC converter must reduce as much as possible the ripple output voltage and the input current. Several methods to reduce the input current ripple have been widely researched [6-11]. Passive solutions, such as filters and electromagnetics shielding, have been used to suppress EMI, but these methods have drawbacks in terms of weight, volume, cost, and efficiency [12]. In general, mitigation techniques of the ripple are effective only on the input or on the output. In particular, the DCDC converters works in high-frequency range and, then, the EMI cannot be filtered by using passive filters. Other solutions, called spread spectrum methods, are based on the idea to spread the spectrum of the converter, such that the power at specific frequencies is reduced to conform to the EMI standards without any additional filters. In recent years, the application of spread spectrum techniques in power converters has been widely studied and implemented [13-17]. In this work, the authors have studied the low input current ripple DC-DC quadratic boost converter topologies proposed in [8] and [9]. Differently, here, the aim is to reduce the ripple both on input current and output voltage and, then, to mitigate the EMI disturbances of the converters comparing different solutions. In particular, [8] proposes the converter topology with uncoupled inductors, whereas in [9], the effect of coupled inductor is analysed and optimized. In this paper, the authors have implemented two solutions: the first is based on a band stop notch filter placed in the output of the DC-DC converter with coupled inductors and the latter consists on a software solution based on a random pwm spread spectrum technique to drive the same topology of the converter without coupled inductors. In this way, a comparison between hardwarebased and software-based solution is performed. Simulation models of the two solutions have been obtained using Matlab/Simulink, and their performance characteristics are compared and discussed. The planning of the paper is the following. Section 2 outlines the operation of the DC-DC converter under study with and without coupled inductors. Both a hardware and software ripple reduction technique are proposed in Section 3. In Section 4, case studies are carried out, and corresponding simulation results are presented. Finally, Section 4 deals with the comparison of the results. 


\section{Power Converters Topology under study}

The topology of the circuits under study is shown in Figure 1 and Figure 2. They differ for the coupling inductor. In the following, only the fundamental of the operation are given; further details can be found in ref. [8] and [9].

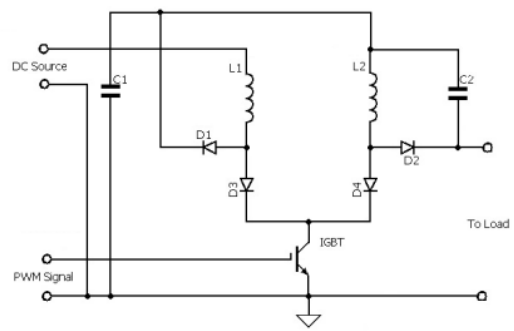

Fig.1. Circuit scheme of the quadratic converter topology with uncoupled inductors.

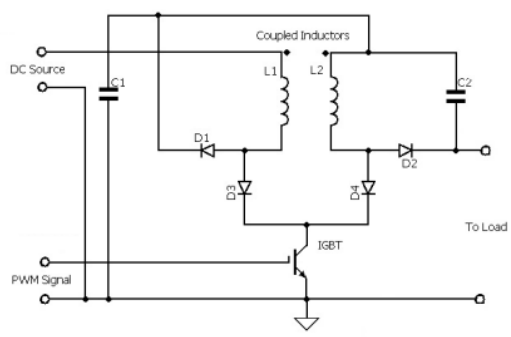

Fig.2. Circuit scheme of the quadratic converter topology with coupled inductors.

\section{A. Operation of the quadratic converter with uncoupled inductors.}

In this analysis, all components are considered as ideal. It means that the on-state resistance $\mathrm{R}_{\mathrm{DS}(\mathrm{ON})}$ and all parasitic capacitors of the switch $S$ are neglected, the forward voltage drop of the diodes D1-D4 are ignored, and that capacitors $\mathrm{C} 1$ and $\mathrm{C} 2$ are sufficiently large so that the voltage across $\mathrm{C} 1$ and $\mathrm{C} 2$ remains constant during one switching period.

The operation, within a switching period, $\mathrm{T}$, is the following:

- Mode 1 - ON state $\left[\mathrm{t}_{0} ; \mathrm{t}_{\mathrm{on}}\right]$ : in this time range, the switch $\mathrm{S}$, the diodes $D_{4}$ and $D_{3}$ are turned on, whereas the diodes and $D_{l}$ and $D_{2}$ are turned off. The input voltage source is connected to the inductor $L_{l}$ and the energy of the source is transferred to this inductor. In this stage, the capacitors $C_{1}$ and $C_{2}$ supply energy to the output load, and a part of the energy, stored in $C_{2}$, supplies the inductor $L_{2}$ as well.

- Mode 2- OFF state $\left[\mathrm{t}_{\mathrm{on}} ; \mathrm{T}\right]$ : in this time range, the switch $\mathrm{S}$, the diodes $D_{4}$, and $D_{3}$ are turned off and $D_{1}$ and $D_{2}$ are turned on. The inductors $L_{1}$ and $L_{2}$ deliver their energy to the load and to the capacitors $C_{2}$ and $C_{l}$, respectively.

The average value of the two currents, $\bar{I}_{L 1}$ and $\bar{I}_{L 2}$, as derived in [8] are given by:

$$
\begin{aligned}
\bar{I}_{L 1} & =\frac{P_{\text {in }}}{V_{\text {in }}} \quad \bar{I}_{L 2}=\frac{V_{\text {in }}}{R(1-D)^{3}} \\
V_{C 1} & =V_{\text {in }} \frac{D}{(1-D)^{2}} \quad V_{C 2}=\frac{V_{\text {in }}}{(1-D)}
\end{aligned}
$$

$$
G=\frac{V_{o}}{V_{\text {in }}}=\frac{V_{C 1}+V_{C 2}}{V_{\text {in }}}=\frac{1}{(1-D)^{2}}
$$

where $V_{\text {in }}$ is the input voltage, $\mathrm{P}_{\text {in }}$ is the maximum rated power, $D$ is the duty cycle and $\mathrm{R}$ the output resistive load.

\section{B. Operation of the Quadratic converter with coupled} inductors.

In the converter topology with coupled inductors, the inductors $\mathrm{L}_{1}$ and $\mathrm{L}_{2}$ are coupled in opposite winding orientation, with mutual inductance, $\mathrm{M}$ [9]. To analyse the operating principle of this converter, the topology can be represented by an equivalent circuit with two, it can be represented by an equivalent circuit with two uncoupled inductors $\mathrm{L}_{1 \mathrm{eq}}$ and $\mathrm{L}_{2 \mathrm{eq}}$ given by [9]:

$$
\begin{array}{cc}
L_{1 e q}=\frac{L_{1} n(1-D)\left(1-k^{2}\right)}{n(1-D)+k} & L_{2 e q}=\frac{L_{2}\left(1-k^{2}\right)}{1-n k(1-D)} \\
k=\frac{M}{\sqrt{L_{1} L_{2}}} & n=\sqrt{\frac{L_{2}}{L_{1}}}
\end{array}
$$

the analysis of the operating modes, within a period $T$, of the coupled inductors converter becomes the same of the uncoupled inductors converter with, (see figure 1 ), $\mathrm{L}_{1}=$ $\mathrm{L}_{\text {leq }}, \mathrm{L}_{2}=\mathrm{L}_{2 \mathrm{eq}}$ and $\mathrm{M}=0$. For the quadratic converter topology, the inductor currents $i_{L 1}$ and $i_{L 2}$ are obtained by the superimposition of the ripple component $i_{1}$ and $i_{2}$ over the dc component, $i_{L 1 m i n}$ and $i_{L 2 m i n}$, respectively, it represents the initial and final values of inductor currents in each switching interval [9]:

$$
\begin{gathered}
i_{L 1}=i_{1}+i_{L I \min } \quad i_{L 2}=i_{2}+i_{L 2 \min } \\
i_{L 1}(t)=\frac{V_{\text {in }}}{L_{1}} \frac{n(1-D)+k}{n(1-D)\left(1-k^{2}\right)} t+i_{1 L \min } \\
i_{L 2}(t)=\frac{n k(1-D)+1}{(1-D)\left(1-k^{2}\right)} t+i_{2 L \min } \\
i_{L 1 \min }=\frac{P_{i n}}{V_{i n}}-\frac{V_{i n} D T}{2 L_{1 e q}} \\
i_{L 2 \min }=\frac{V_{i n}}{R(1-D)}\left[\frac{1}{(1-D)^{2}}-\frac{D R T}{2 L_{2 e q}}\right]
\end{gathered}
$$

Moreover, the ripple of the inductors currents, $\Delta I_{L 1}$ and $\Delta I_{L 2}$, is:

$$
\begin{aligned}
& \Delta I_{L 1}=i_{L 1(D T)}-i_{L 1 \min }=\frac{V_{i n}}{L_{1}} \frac{n(1-D)+K}{n(1-D)\left(1-k^{2}\right)} D T=\frac{1}{L_{1 e q}} V_{i n} D T \\
& \Delta I_{L 2}=i_{L 2(D T)}-i_{L 2 \min }=\frac{V_{i n}}{L_{2}} \frac{1-n k(1-D)}{(1-D)\left(1-k^{2}\right)} D T=\frac{1}{L_{2 e q}} \frac{V_{\text {in }}}{(1-D)} D T
\end{aligned}
$$

For $\mathrm{k}=0$, eq. (7) - (12) give the related values in the converter with uncoupled inductors $\left(\mathrm{L}_{1 \mathrm{eq}}=\mathrm{L}_{1}\right.$ and $\mathrm{L}_{2 \mathrm{eq}}=\mathrm{L}_{2}, \mathrm{M}=0$ ). In [9] it has been demonstrated that the output voltage gain equation is the same for the two topologies of the quadratic converter (eq. 3).

Equation (11) shows that the ripple on the input current depends on three design parameters: $D, k$, and $n$. 
Therefore, for a given value of $k$ and $n$, a value of duty ratio, $D_{\text {zero }}$, that ensure the free ripple input current condition, i.e., $\Delta \mathrm{i}_{\mathrm{L} 1}=0$, can be calculated as:

$\mathrm{D}_{\text {zero }}=1+\frac{\mathrm{k}}{\mathrm{n}} \quad$ where $\quad 0 \leq \mathrm{D}_{\text {zero }} \leq 1$

the equation (11) shows that, once defined the value of $D_{\text {desidered }}$ and $n_{\text {desidered }}$ during the design step, it is possible to compute a specific value of the coupling coefficient, $k^{*}$, that assures an input free ripple condition $\left(D_{\text {desired }}=\right.$ $D_{\text {zero }}$ ):

$$
k^{*}=\left|\frac{\left(1-\sqrt{\left(1+8 \cdot n^{2} \cdot(1-D)^{2}\right.}\right.}{2 \cdot n \cdot(1-D)}\right|
$$

$$
\Delta_{\text {iL1coupl }} \leq \Delta_{\text {iL1uncoupl }} \quad k \leq k^{*}
$$

The input current ripple vs duty ratio for several value of $\mathrm{k}$ and fixed $\mathrm{n}$ is shown on figure 3 . It can be noted that the choice of $k$ allows the ripple to be reduced.

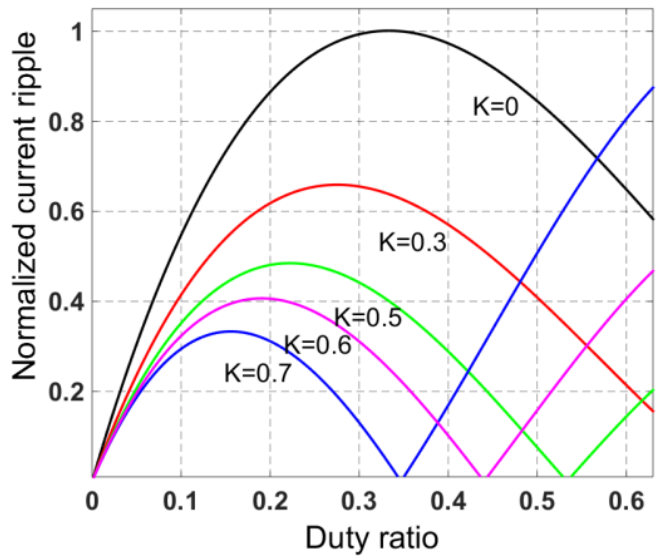

Fig.3. Input current ripple vs duty ratio for several value of $\mathrm{k}$ and fixed $n$.

\section{Ripple Reduction Techniques of a Quadratic DC-DC Converter}

This work aims to compare two different solutions to reduce the output voltage ripple and the input current ripple of a quadratic DC-DC converter. In particular, the authors have designed a software solution based on the random PWM technique to drive the uncoupled quadratic converter and a hardware solution based on a modification of the coupled quadratic converter controlled by a classic PWM. The performance of the two solutions is evaluated and compared.

\section{A. Random PWM Technique}

The random switching techniques are widely applied to power converter to reduce electromagnetic interferences (EMI). The random PWM (RPWM) techniques spread the power spectral density (PSD) of the conducted disturbances over a wide frequency range, reducing its amplitude respect to the classic PWM scheme. The algorithm proposed in this paper allows obtaining a PWM signal with random frequency $\mathrm{f}$, where the duty cycle $D$ is constant, and the frequency changes casually after a number of a fixed number of pulses $N$ (see figure 6). In figure 4 is shown the logic diagram of the proposed algorithm to generate the random PWM. A random generator gives a value of the frequency $\mathrm{f}^{*}$ of a sawtooth signal randomly chosen in the range $f_{\min }-f_{\max }$. The duty cycle value of the RPWM is fixed; it defines the reference value $\mathrm{u}^{*}$ gives to the comparator. This one outputs a high logical level when the amplitude of the sawtooth signal is higher than $\mathrm{u}^{*}$, otherwise, a low logical level is given (see figure 5). In this way, the comparator outputs a PWM signal with duty cycle $D$ and a frequency $f^{*}$. A pulse counter counts the number of pulses $\mathrm{n}$ of the RPWM signal and this number is compared whit the value $N$. The random generator gives a new value of the random frequency when $n$ is equal to $\mathrm{N}$. Moreover, a signal is generated to reset the pulse counter to obtain a PWM signal whit fixed duty cycle D and a frequency that changes casually after every $\mathrm{N}$ pulses. Figure 6 shows the RPWM generated by the proposed algorithm.

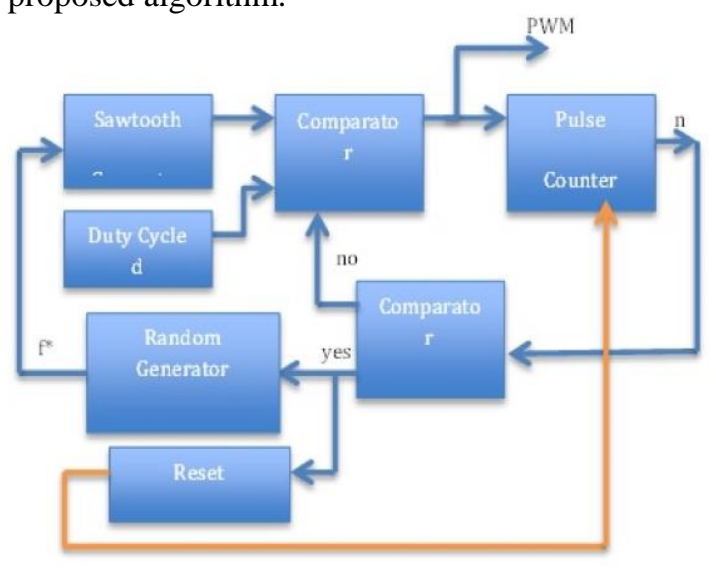

Fig.4. Logic Diagram of the Random PWM algorithm.

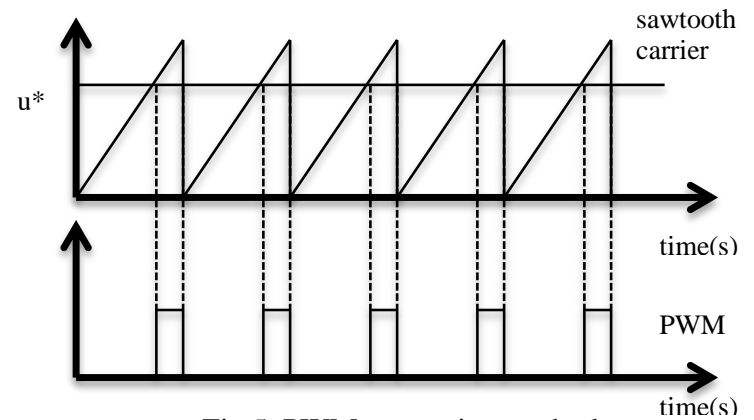

Fig.5. PWM generation method

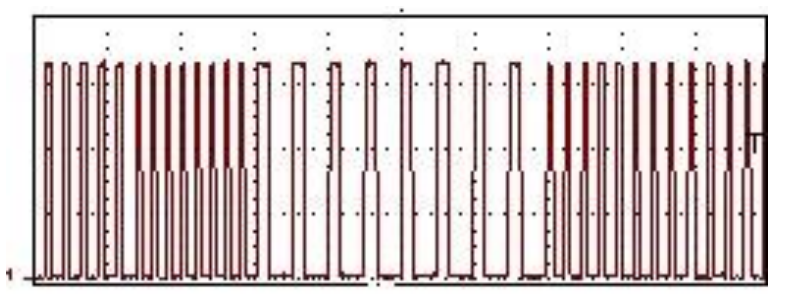

Fig.6. Random PWM segnal proposed.

B. Hardware solution to reduce the input and output ripple.

The quadratic converter with coupled inductors, shown in figure 2 allows deleting the input ripple current when the 
free ripple conditions (eq. 14 and 15) is verified [8] but it does not reduce the voltage output ripple. Following the hardware approach, a notch filter connected in parallel to the load of the converter has been designed to reduce the effect of the switching frequency in the output voltage. It is shown in figure 8. This selective filter is tuned on the first harmonic corresponding to the switching frequency since exhibits the higher amplitude.

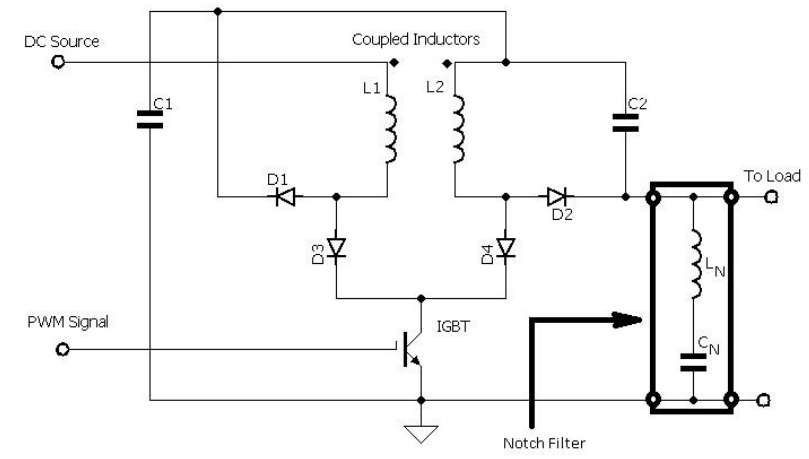

Fig.8. Circuit scheme of the quadratic converter topology with coupled inductors and notch filter.

In fact, the output voltage ripple mainly depends on the amplitude of the spectrum line at the switching frequency. The notch filter is a pass-band filter that allows a cheap realization since only a slight current at the switching frequency will flow through it, limiting the power loss. This hardware solution represents a good solution for the proposed DC-DC converter, which is characterized by low power and small size. In this application, a solution based on an active compensator is not suitable for cost and size [18]. To reduce the converter output voltage ripple, the notch filter is designed according to the following condition at the switching frequency $f_{s}$ :

$$
\begin{gathered}
\omega_{s} L_{n}=\frac{1}{\omega_{s} C_{n}} \quad \omega_{s}=\frac{1}{\sqrt{L_{n} C_{n}}} \\
Z_{n o t c h}(j \omega)=R_{s}+j\left(\omega L_{n}-\frac{1}{\omega C_{n}}\right) \\
Z_{n o t c h}\left(j \omega_{s}\right)=R_{s} ; B \text { Bandwidth }=B=\frac{f_{s}}{Q}=\frac{R_{s}}{2 \pi L}
\end{gathered}
$$

where the notch impedance $\boldsymbol{Z}_{\text {notch }}$ is equal to the parasitic resistance $R_{s}$ of the filter components $L_{n}$ and $C_{n}$ in nonideal conditions $\left(\mathrm{R}_{\mathrm{s}} \neq \mathbf{0}\right)$. For this reason the ac converter output voltage is not equal to zero at the switching frequency and its reduction depends on the value of the notch parasitic resistance $R_{s}$. Furthermore, the value of the filter bandwidth $\mathrm{B}$ depends on the value of this resistance and it is very narrow if $R_{s}$ is very little. Therefore, the notch filter components $L_{n}$ and $C_{n}$ have to be chosen suitably in order to have a notch filter with a parasitic resistance $R_{s}$ that offers a good trade-off between the filter bandwidth value and a enough reduction of the output voltage ripple. The commercial values of the components adopted for the notch filter are:

$$
L n=1.2 \mu \mathrm{H} \quad C n=50 \mu \mathrm{F}
$$

\section{Simulation Results}

The simulation models of the ripple reduction methods for the DC-DC converters studied have been created using Matlab/Simulink. Therefore, the performances of these solutions are verified and discussed. The simulations have been made considering four different scenarios: a) the converter without coupled inductors driven by classical PWM, b) the converter with coupled inductors driven by classical PWM, c) the converter with coupled inductors and notch filter driven by classical PWM, and d) the converter without coupled inductors driven by random PWM. The simulation results allow comparing the several solutions proposed by the authors in terms of input current ripple, output voltage ripple, and EMI disturbances. The electrical parameters of the DCDC converter topologies implemented are shown in Table I.

Figures 9,10,11 and 13 show the input current and output voltage waveforms of the DC-DC converter topologies under study in the different scenarios. In particular, figure $a$ shows the input current and the output voltage versus time and $b$ and $c$ the frequency spectrums of these waveforms. Figure 12 shows the pulsation of PWM signal implemented randomly variable. Table II summarizes the performance of the different scenarios in terms of input current-output voltage ripple, and the amplitude of the input current-output voltage at the switching frequency $(20 \mathrm{KHz})$.

As can be seen, a very low input current ripple characterizes the two DC-DC converter topologies studied. In particular, the coupled inductors allow reducing more of the current ripple. The simulated scenarios with the DC-DC converter with coupled and uncoupled inductors driven by a classical PWM show that the output voltage ripple is comparable. The proposed solutions with coupled inductors using the notch filter driven by a classical PWM reduces the voltage ripple to a value equal about to one half. It should be remarked that the values of $\Delta V_{\text {out }} p$ p and $\Delta I_{\text {in_pp }}$ are calculated as the difference between the maximum and the minimum value. They correspond to the ripple only in the first three cases, whereas for random modulation, it gives only the maximum variation since the variation of the switching frequency makes the ripple variable.

It is also of interest the comparison of the power calculated by the integral of the spectral power density (SPD) of the obtained waveforms. The SPD is calculated based on the Discrete Fourier Transform; the power density considers the square of the voltage and of the current The resulting power takes into account the contributions in the whole range of frequency. It has to be remarked that since the results are referred to a conventional load of $1 \Omega$, they are meaningful in comparison. Results are summarized in table III where the percent variation, compared to the traditional PWM with uncoupled inductor topology, is calculated as well. Only the random modulation reduces the whole power on the output voltage significantly; on the contrary, the coupled inductors lessen the power associated with the input current independently of the notch filter. It requires hence a further EMI suppression at high frequencies. 

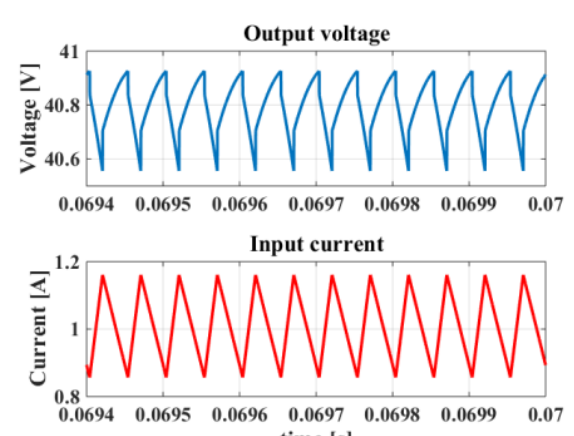

time [s]

(a)

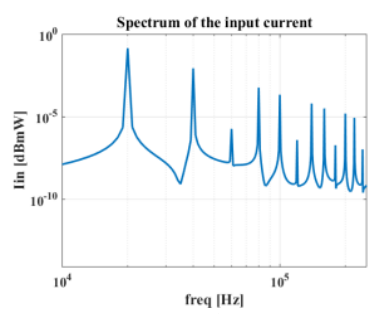

(b)

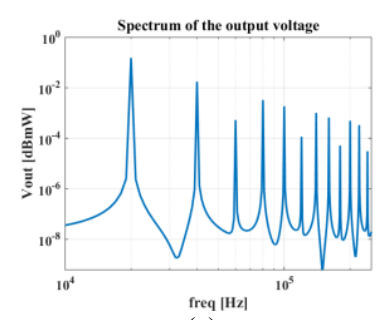

(c)
Fig.9. Input current and output voltage waveforms of the converter without coupled inductor with classical PWM.
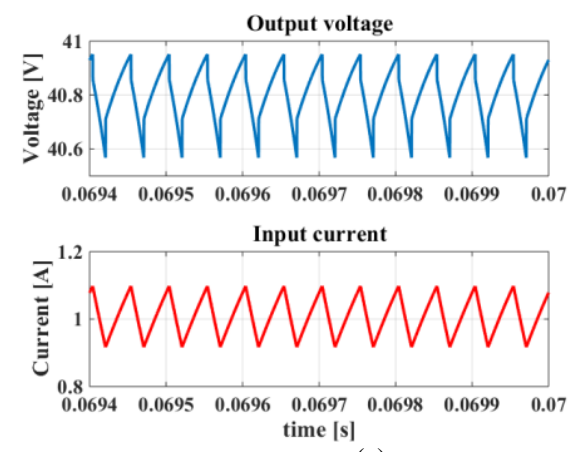

(a)

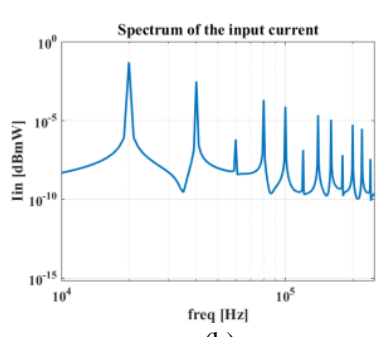

(b)

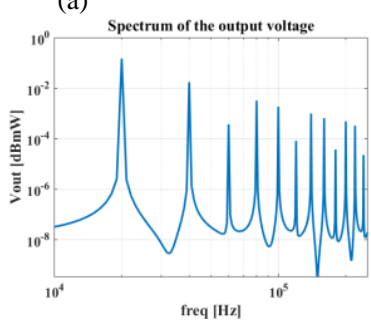

(c)
Fig.10. Input current and output voltage waveforms of the Converter with coupled inductor with classical PWM.
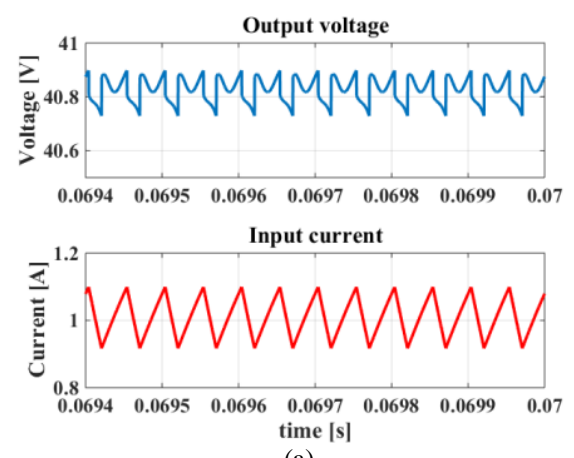

(a)

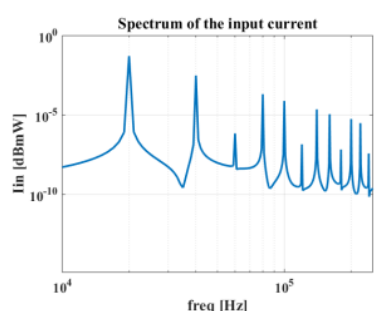

(b)

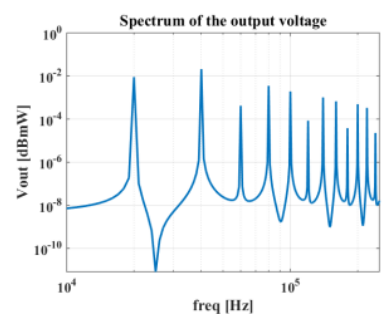

(c)
Fig.11. Input current and output voltage waveforms of the Converter with coupled inductor and notch filter with classical PWM.

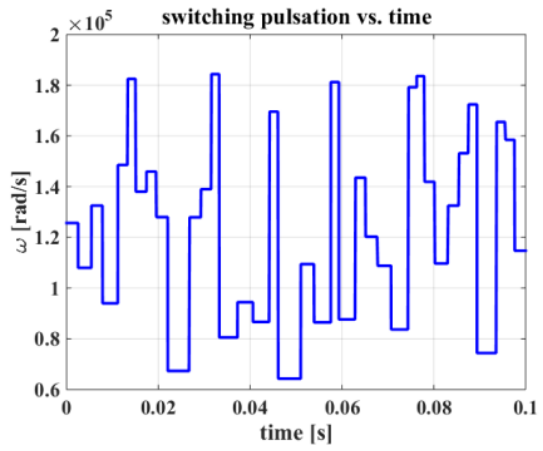

Fig.12 Variation of the switching pulsation due to the Random PWM
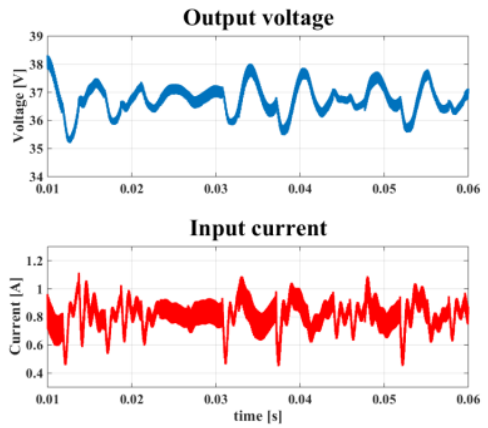

(a)

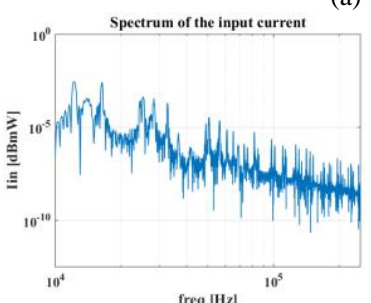

(b)

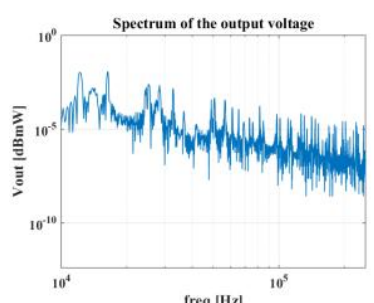

(c)

Fig.13 Input current and output voltage waveforms of the Converter without coupled inductor with random PWM.

Table I. DC-DC converter parameters.

\begin{tabular}{|c|c|}
\hline Input Voltage $\mathrm{V}_{\text {in }}$ & $20 \mathrm{~V}$ \\
\hline Switching frequency $\mathrm{f}_{\mathrm{s}}$ & $20 \mathrm{KHz}$ \\
\hline Duty Cycle & 0,30 \\
\hline $\mathrm{L}_{1 \text { dis }}$ & $1 \mathrm{mH}$ \\
\hline $\mathrm{L}_{1 \text { dis }}$ & $1 \mathrm{mH}$ \\
\hline $\mathrm{C}_{1}$ & $100 \mu \mathrm{F}$ \\
\hline $\mathrm{C}_{2}$ & $100 \mu \mathrm{F}$ \\
\hline $\mathrm{Rc}_{1 \mathrm{~s}}$ & $0.05 \Omega$ \\
\hline $\mathrm{Rc}_{2 \mathrm{~s}}$ & $0.05 \Omega$ \\
\hline Coupling coefficient $\mathrm{k}$ & 0,82 \\
\hline $\mathrm{R}_{\text {Load }}$ & $92 \Omega$ \\
\hline
\end{tabular}


Table II. Comparison of the proposed solutions

\begin{tabular}{|c|c|c|c|c|}
\hline & $\begin{array}{c}\Delta \text { Vout_pp } \\
{[\mathrm{V}]}\end{array}$ & $\begin{array}{c}\Delta \operatorname{Iin}[\mathrm{A}] \\
{[\mathrm{pp}}\end{array}$ & $\begin{array}{c}\text { Vout(20KHz) } \\
{[\mathrm{dBmW}]}\end{array}$ & $\begin{array}{c}\operatorname{Iin}(20 \mathrm{KHz}) \\
{[\mathrm{dBmW}]}\end{array}$ \\
\hline $\begin{array}{c}\text { Decoupled } \\
\text { inductors }\end{array}$ & 0.371 & 0.304 & 0.153 & 0.145 \\
\hline $\begin{array}{c}\text { Coupled } \\
\text { inductors }\end{array}$ & 0.384 & 0.182 & 0.152 & 0.052 \\
\hline $\begin{array}{c}\text { Notch } \\
\text { filter }\end{array}$ & 0.169 & 0.182 & 0.021 & 0.052 \\
\hline $\begin{array}{c}\text { Random } \\
\text { mod. }\end{array}$ & $2.5492^{*}$ & $0.6408^{*}$ & 0.3066 & 0.0233 \\
\hline
\end{tabular}

Table III: Power calculated by Spectral Power density

\begin{tabular}{|c|c|c|c|c|}
\hline & Vout & $\Delta$ Vout/V & In & $\Delta \operatorname{Iin} / \mathrm{I}$ \\
\hline $\begin{array}{c}\text { Decoupled } \\
\text { inductors }\end{array}$ & $8.3457 \cdot 10^{6}$ & - & $2.4434 \cdot 10^{4}$ & - \\
\hline $\begin{array}{c}\text { Coupled } \\
\text { inductors }\end{array}$ & $8.3457 \cdot 10^{6}$ & 0 & $1.1994 \cdot 10^{4}$ & $-51 \%$ \\
\hline Notch filter & $8.3420 \cdot 10^{6}$ & $-0.044 \%$ & $1.2070 \cdot 10^{4}$ & $-51 \%$ \\
\hline Random mod. & $5.7191 \cdot 10^{5}$ & $-93 \%$ & $2.0956 \cdot 10^{4}$ & $-14 \%$ \\
\hline
\end{tabular}

\section{Conclusion}

A quadratic boost converter has been analysed to highlight the reduction of the ripple in the output voltage and in the input current by different solutions based on a hardware and software approach, respectively. In particular, hardware solution employs coupled inductors and an output notch filter with a fixed frequency PWM. In contrast, the software solution exploits a random modulation algorithm to spread the spectrum lines.

The traditional quadratic converter with decoupled inductor has been compared with the same topology but considering the inductor coupled. Then a notch filter has been placed at the output to suppress the harmonic at the switching frequency and finally, a random PWM modulation has been tested.

Results show that the output voltage ripple is minimized only by the notch filter, instead the input current ripple is reduced by the presence of the coupled inductor. The random modulation exhibits a higher difference between maximum and minimum ripple both of the current and on the voltage since the ripple varies with the switching frequency but reduces drastically the power associated with the whole spectrum.

\section{References}

[1] L. Jiang, W. Zhang, D. Dong, I. Cvetkovic, F.C.Lee, P.Mattavelli, D. Boroyevich and P. Kong, "R-based MPPT Method for Smart Panel PV system," IEEE APEC 2012, FL, USA, Feb. 2012.

[2] G. Fontes, C. Turpin, R. Saisset, T.Meynard and S. Astier, "Interactions between fuel cells and power converters influence of current harmonics on a fuel cell stack," IEEE Power Electron. Specialist Conf., Aachen, Germany, June 2004.

[3] Koponen, Joonas, et al. "Effect of Converter Topology on the Specific Energy Consumption of Alkaline Water Electrolyzers." IEEE Transactions on Power Electronics 34.7 (2018): 6171-6182. [4] M. Laour, R. Tahimi, C. Vollaire - "Modeling and Analysis of Conducted and Radiated Emissions Due to Common Mode Current of Buck Converter" - IEEE Trans. on Electromagnetic Compatibility, Vol. 59, No. 4, Aug. 2017.

[5] A. Lai, I. L. Spano, I. Marongiu, G. Gatto - "EMC Assessment of a Switching Mode Power Supply for Electromedical Devices" - Proc. Of the 2016 Inter. Symposium on Electromagnetic Compatibility - EMC Europe 2016, 5-9 Sept. 2016, Wroclaw, Polland.
[6] G. Y. Choe., H. S. Kang, B. K. Lee, W. Y. Lee, "Design Consideration of Interleaved Converters for Fuel Cell Applications," Inter. Conf. Electrical Machines and Syst. 2009. [7] P.W. Lee, Y. S. Lee, K. W. Cheng, X. C. Liu, "Steady-State Analysis of an Interleaved Boost Converter with Coupled Inductors," IEEE Trans. on Ind. Electr., vol.47, no 4, Aug. 2000.

[8] G. Marsala, M. Pucci, R. Rabbeni, G. Vitale, "Analysis and design of a dc-dc converter with high boosting and reduced current ripple for PEM FC," IEEE Vehicle Power Propul. Conf., 2011.

[9] G. Marsala, A. Ragusa - "Free Ripple Input Current High Boost Converter with Coupled Inductors"- Proc. of 5th Int. Conf. on Electric Utility Deregulat. and Restruct. and Power Techn. (DRPT 2015), Changsha, Cina, Nov 2015.

[10] F. Alonge, M. Pucci, R. Rabbeni, G. Vitale, "Sensitivity analysis of a High Gain DC/DC boost converter including parasitic parameters", Ren. Energy \& Power Quality Journal, Vol.1, No.14, May 2016, RE\&PQJ-14 ISSN 2172-038X I.

[11] D.K. Saini, A. Ayachit, T. Salvatierra, M.K. Kaziemierczuk, "Design of zero-voltage-ripple buck dc-dc converter", 60th International Midwest Symposium on Circuits and Systems (MWSCAS), Aug. 6-9, 2017, Boston, MA, USA.

[12] Shuo Wang, F.C. Lee, D.Y. Chen, W.G: Odendaal, "Effect of parasitic parameter on EMI filter performance" , IEEE Trans., vol 1, no 3, pp. 869-877, May 2004.

[12] G. Marsala, A Ragusa - "Spread Spectrum in Random PWM DC-DC Converters by PSO\&GA Optimized Randomness Levels" - submitted to 2017 IEEE 5 th Inter. Symposium on Electromagnetic Compatibility, EMC 2017, Oct. 19-22, 2017, Beijing, China.

[13] G. Marsala, A Ragusa - "Chaos PWM for EMI reduction in high boost DC-DC converter with coupled inductors " submitted to 2017 IEEE 5 th Inter. Symposium on Electromagnetic Compatibility, EMC 2017, Oct. 19-22, 2017, Beijing, China.

[14] G. Marsala, A Ragusa - “ A GA-neural network harmonic minimization method for multilevel inverters with unequal DC sources for different modulation index values"- submitted to 2016 IEEE 19 th Inter. Conference on Electrical Machines and Systems, ICEMS 2016, Nov. 13-16, 2017, Chiba, Japan.

[15] G. Marsala, A Ragusa - "Mitigation of EMI in a coupled inductors-high boost DC-DC converter by programmed PWM " 2017 IEEE $5^{\text {th }}$ Inter. Symposium on Electromagnetic Compatibility, EMC 2017, Oct. 19-22, 2017, Beijing, China.

[16] Yen-Shin Lai, So-Yuan Chen, "Two-dimensional Random PWM Technique for Full-Bridge DC/DC Converter" , 38th Annual Conference on IEEE Industrial Electronic Society (IECON), Oct. 25-28, 2012, Montreal, Canada.

[17] K. K. Tse, Henry Shu-hung Chung, S. Y. R. Hui, H. C. So, "A Comparative Investigation on the Use of Random Modulation Schemes for DC/DC Converters", IEEE Transaction on Indust. Electr., Vol. 47, No. 2, April 2000.

[18] H. Martínez-García, A. Grau-Saldes, "Capacitorless DCDC Converter", IEEE Emerging Technology and Factory Automation (ETFA), Barcelona, Spain, Sept. 2014.

Future developments: the results are going to be verified experimentally by a test rig on a prototype of the converter under construction.

\section{Authors' contributions:}

$G$. Marsala and $G$. Vitale conceived and designed the analysis, wrote the paper.

$V$. Presti conceived the random algorithm, implemented the circuits for simulation and wrote the paper.

S. G. Scordato and A. Sauro arranged the hardware for simulations, prepared a circuit prototype with the devices tested in simulation for experimental verification. 